\title{
Building Literacy Communities of Practice Across Subject Disciplines in Secondary Schools
}

\author{
Noeline Wright \\ School of Education, University of Waikato, Hamilton, New Zealand
}

This paper examines the relationship between communities of practice and literacy as a pedagogical focus in secondary schools in New Zealand in the light of Corson's arguments about critical conditions for effective language policy development in schools. It is also positioned within the current international emphasis (at least in English-speaking countries) on improving students' literacy in order to increase academic achievement. Part of this focus stems from an unbalanced relationship between learning mainly content (what) and learning processes (how and why) through content in secondary school classrooms. If teachers' work is centred on equipping students with the learning and thinking tools that allow them to navigate, make sense of and critically examine subject content, then literacy as a pedagogical focus can be seen as supporting that shift. However, shifting secondary teachers to a focus on learning and thinking processes can be difficult, because it implicates their pedagogical values, practices and pedagogical content knowledge (PCK). How schools in New Zealand have developed this focus and made efforts to sustain it are examined through the concept of communities of practice.

doi: $10.2167 / / e 800.0$

Keywords: literacy, communities of practice, secondary schools, professional development, pedagogical content knowledge

\section{Introduction}

This paper ${ }^{1}$ examines the notion of communities of practice (Buysse et al., 2003; Lave \& Wenger, 1991) in the light of both Corson's (1999) arguments about critical conditions for effective language policy development in schools, and the current international emphasis (at least in English-speaking countries) on improving students' literacy as a vehicle for improving academic achievement. A linked concern is how to address some of the impediments to change, such as the 'complexities of classroom practice' (Moje et al., 2000: 165). Some questions arise as a result: what do the terms 'literacy' and 'community of practice' mean? And what are some issues in changing teachers' practices? The paper begins with a brief examination of notions of literacy in a secondary school context. The paper then proceeds to examine the role communities of practice may have in sustaining a literacy focus for pedagogy in secondary schools.

'Literacy' is often assumed to mean reading and writing, principally, of printed texts, in English (cf. Smyth, this issue). To help conceptualise the possibilities for meanings of literacy, Gee (2003) argues that '... learning is not just a matter of 
what goes on inside people's heads but is fully embedded in (situated within) a material, social and cultural world' (p. 8). In other words, literacy is a concept that can no longer be thought of as being only about print; rather, it can more properly be thought of as a semiotic domain: 'any set of practices that recruits one or more modalities (e.g. oral or written language, images, equations, symbols, sounds, gestures, graphs, artifacts, etc.) to communicate distinctive types of meanings' (Gee, 2003: 18; see also May, this issue).

One reason for reviewing ideas about literacy is that the knowledge and understanding some current teachers have (especially in secondary schools) tends to be rooted in a past that had the written and spoken word as prime sources of formal learning. This is partially a result of the kinds of learning teachers experienced themselves, since it is common for people to replicate what they know and have grown up with. However, 21st century school students learn through a much wider range of communication technologies than current teachers were ever exposed to in their childhoods. This difference is highlighted in the strong content focus of secondary teachers. In other words, many tend to concentrate attention on the content of their subject domains (in which they have become expert), rather than the learning processes and social practices of these disciplines, because that is what has served them well until now. Facts are frail, and they become less absolute as new knowledge is created and uncovered. This suggests that a singular content focus is no longer sufficient; teachers need to focus on the means by which knowledge is created (e.g. how and why), as well as content (e.g. what, who, where and when), so that students are well equipped to critically engage with an information-rich world. Whitehead's (this issue) contention that secondary school teachers' pedagogies are too focussed on content at the expense of the literacy, and thinking tools that help students construct knowledge supports this.

This unbalanced relationship between learning mainly content (what) and learning processes (how and why) through content can be understood as the distance between what teachers know and can do, and what students know and can do. To put it another way, teachers' work should be centred on equipping students with the learning and thinking tools that allow them to navigate, make sense of and critically examine subject content (Wright, 2003). However, switching teachers to a focus on learning and thinking processes can be difficult, because it implicates their pedagogical practices and pedagogical content knowledge (PCK). The complexities of classroom and wider school relationships, including the imperatives of national examinations and qualifications, are also involved. Unfortunately, traditional practices related to teachers' professional knowledge have tended to centre on technicist views of both learning and the role of teachers. Coldron and Smith (1999: 720) observe that:

...technical-rationalist views of teaching... assume that educational problems (e.g. inadequate attainment levels of children in reading) can be isolated and effective responses can be identified (e.g. good practice in the teaching of reading). It follows that if enough teachers are trained to copy that good practice then the problem will be solved.

These assumptions have been shown to be wanting, because there continues to be a mismatch between teachers' PCK and what students need beyond 
school. New knowledge about teacher learning suggests three themes. Putnam and Borko (2000), for instance, believe that cognition is situated in particular physical and social contexts, it is social in nature, and is 'distributed across the individual, other persons, and tools' (p. 4). This, therefore, requires a different orientation from the traditional Professional Development (PD) provisions teachers have experienced until now (cf. Smyth, this issue). As the Ministry of Education (2003) Programme for International Student Assessment (PISA) report observed regarding New Zealand students' knowledge of learning processes, 'once students leave school they must manage most of their learning for themselves. Therefore, instilling in students a well-developed ability to manage their own learning should be a major goal of schooling' (p. 19). These same PISA results identified that New Zealand has a long achievement tail.

So, how should teachers reinvent their pedagogical practices to support students' current and future learning needs? A framework that supports teachers' professional knowledge, based on their social, pedagogical and physical contexts, is required.

A specific focus on literacy is one method by which the New Zealand government hopes to bridge learning gaps and reduce its PISA-identified 'literacy tail'. But if literacy is expected to be a vehicle for improving students' highlevel thinking and their ability to critique and produce knowledge (and, by implication, improving their academic achievement and capabilities for lifelong learning), then it follows that the traditional approaches of short term PD for teachers had to change. The single-day courses of classroom strategies and activities, for instance, that have long characterised PD, were often devoid of much theoretical underpinning, and tended to centre on content delivery rather than developing understanding of learning processes. Conspicuous absences within day courses included much reference to school change processes, literacy and thinking approaches, theory and research or analyses of relevant data (both qualitative and quantitative) to monitor either the progress of student literacy achievement or teachers' perceptions of literacy teaching and learning.

Recent New Zealand research into literacy in secondary schools (via the SSLI) has demonstrated the insufficiency of a short term PD focus on privileging content. The research evaluations have subsequently informed the development of national PD models, including longer, slower, more in-depth literacy facilitation targeting fewer schools and engaging with teachers at deeper levels over 2 years. This new focus allows schools to more fully develop structures and processes that sustain literacy approaches across the curriculum and over time (see May, this issue).

Improving students' academic achievement through teachers' altering pedagogical approaches to emphasise literacy, critical thinking and learning processes does not come easily: it is neither linear nor straightforward nor a technical process. Instead, it involves teachers' emotions, relationships and their professional identities (Hargreaves, 1997). And Albrecht (2003) has argued that organisations are unlikely to instigate change if they crave the status quo. When it comes to pedagogical practices, teachers may prefer the known, familiar, comfortable and safe. However, as school populations and technologies change, processes and modes of learning must respond accordingly (Gee, 2003). This scenario may partially account for the long achievement tail in New Zealand identified through PISA comparisons referred to earlier. 
If the core role of education is to expose students to new learning (Morris \& Stewart-Dore, 1984), then teachers must make the gap between the known and unknown as bridgeable as possible by matching their pedagogy to students and their learning. With these ideas in mind, the concept of 'communities of practice' thus became a lens through which long term pedagogical change centred on literacy within the SSLI research evaluation can be examined.

\section{Communities of Practice (CP)}

A community of practice (CP) is, according to Wenger (1999), a mechanism through which beliefs, attitudes and practices can be re-formed. A CP can be fluid, open and 'organic' (Wenger et al., 2002), build on existing internal networks and be characterised by 'joint enterprise, mutual engagement and shared repertoire ... working for a similar purpose or goal; [doing] things together; and [using] particular resources, tools, and discourses' (Place \& Coskie, 2006: 230). Teachers, through a literacy community of practice (LCP), have spaces within which to share, swap and trial new ways of thinking and teaching, simultaneously reviewing their pedagogical practices and embedding literacy approaches into their everyday teaching. By examining the effects of the trialled literacy learning approaches on their students, teachers involved in the literacy development became more attuned to their responses, needs and attitudes. Coldron and Smith (1999: 715) report that a CP helps teachers to frame themselves in relation to others within specific contexts, some of which they choose for themselves:

An individual teacher's choice is crucially determined by the array of possibilities he or she perceives as available. Those possibilities (ways in which things could be otherwise) are conveyed by the subject traditions and the more general pedagogic traditions that they variously embody, by the practices of the various professional communities to which a teacher belongs, and by external practices brought into critical relation to teaching.

Such social, intellectual and physical contexts can inhibit or enable teachers' abilities to make changes to their professional selves. The external practices noted earlier may partially refer to facilitation by change agents outside of the school, and partially to the experiences of others within the LCP. Also, when students responded positively to pedagogical innovations, as teachers often reported in the SSLI evaluation, teachers increased their experimentation with literacy-oriented approaches. Students themselves reported that the approaches made learning more accessible and comprehensible, increasing their enjoyment and engagement, improving their disposition towards the subject.

SSLI schools that demonstrated effective, sustainable literacy PCK used students' voices to help shape and refine their practices through mechanisms such as focus group interviews and surveys at regular intervals. One school in particular required teachers and subject departments to use students' opinions about learning to inform changes to planning and programmes. Appraisal interviews helped track this alignment and identified continuing issues regarding the literacy demands of subjects. 
Quite often, a literacy orientation within a classroom went hand in hand with opportunities for students to discuss and share their learning with their peers. Many students, during the course of the research evaluation, indicated that such opportunities were helpful in both making sense of new ideas and made learning much more 'fun'. In other words, through teachers actively incorporating literacy-oriented learning within their classrooms, both teachers and students had opportunities to renegotiate what learning and teaching meant. This spilled beyond classroom walls: students talked about it with others-other students, teachers and parents. Likewise, teachers talked to others about their positive experiences; thus, LCPs had the potential to grow wider, have greater depth and continue momentum for far longer than any external intervention's allotted time within the SSLI (Lave \& Wenger, 1991). There is clear evidence of this continued momentum in schools that continue to make literacy and pedagogical changes based on reflective individual and group practices (cf. May, this issue).

Teachers also shared ideas and experiences beyond their subject boundaries. This was a powerful method through which teachers learned how other disciplines practiced learning and thinking. In some ways, LCPs are one of the few spaces within which secondary teachers could compensate for some of the effects of the traditional silo nature of their professional life. Some schools used professional learning groups to develop and deepen teachers' PCK through targeting specific interests that centred on learning. Some examples from those SSLI schools include volunteer groups that met to discuss and learn about things such as literacy assessment tools to guide practice; technological tools (e.g. interactive whiteboards) to support learning; professional reading topics; thinking skills; investigating learning needs of minority students, and differentiated learning.

Another professional space in some New Zealand secondary schools is $\mathrm{Te}$ Kotahitanga, a PD programme aimed at restructuring teachers' thinking about indigenous Maori students (Bishop \& Berryman, 2006). Schools involved in this programme encourage teachers to talk and share across the curriculum, which, in turn, helps teachers participate in cultural practices as 'epistemological principle[s] of learning' (Lave \& Wenger, 1991). A number of schools involved in this project used literacy approaches to support learning practices that encouraged engagement in learning.

Corson (1999) noted that in schools it is better when personal interests and matters of control are approached as open-ended issues for discussion' (p. 79). Both Te Kotahitanga and literacy communities of practice make these achievable through the opportunity for purposeful professional interactions, which include not only subject-oriented staff clusters, but also cross-curricular ones. Corson's 'personal interests and matters of control' can be understood as teachers' efficacy and identities within their classrooms. However, altering comfortable and known processes can create uncertainty. Pedagogical changes involving teachers' hearts and minds (Hargreaves, 1997), and addressing some of the complexities of their professional lives, disrupt existing cultural and social practices at work in a school; the Te Kotahitanga focusses on one such example: literacy is another.

When literacy as a means of making learning more explicit is a focus, teachers often re-examine related facets of school organisation (cf. May, this issue). For instance, as teachers realise some wider implications of different pedagogical 
practices, they may want to reshape programmes both within and across subject boundaries. This is particularly possible when a school's leadership is committed to literacy as a whole-school project. An LCP can support teachers to resist the strong pull to revert to the comfortable and known. Resistance to this pull is easier when spaces exist within which students can respond positively to new practices, and when colleagues can share their own trials, successes and challenges.

As already noted, expecting teachers to change their pedagogical understanding is not straightforward; it involves changing personal and professional beliefs, attitudes and actions. It is, therefore, appropriate to view knowledge and pedagogy not as technical propositions, but as Albrecht's (2003: 178) 'cultural proposition'. It implicates social behaviour and Coldron and Smith's examination of teachers' professional identities. These aspects complement Gee's argument about what constitutes effective learning processes for students growing up digitally proficient.

Gilbert's (2005) ideas about what kind of knowledge and education are likely to count in the future are also relevant here. She argues that 'the world outside education is increasingly valuing the ability to learn - knowing how to learn, how to keep learning, how to learn with others - over the ability to master specific bits of knowledge' (p. 67; author's emphasis). And since 'emotions figure predominantly in social behaviour ... and are significant because they make possible the social regulation of behaviour' (Marcus \& Kitayama, 1994: 90), LCPs have potential to not only reform teachers' pedagogies at both the process and strategic levels (see also Smyth, this issue), but also at the professional identity level. To exemplify this process, the particular characteristics of the New Zealand 3-year literacy PD project (SSLI) will be discussed next.

\section{Developing literacy communities of practice (LCP) in New Zealand secondary schools}

One consistent mechanism of the literacy facilitation within the secondary schools' literacy evaluation project (SSLI) has been the appointment of schoolbased literacy leaders (LLs). The LL was intended to become not only the link between the external Regional Literacy Facilitator (RF) and the school, but also the internal facilitator for literacy within individual schools. In some schools, this occurred because the LL was provided with a reasonable time allowance to work with a literacy team as a group and one-on-one, observe classroom practices and foster literacy networks within, across and outside of the school. Literacy teams were, at least initially, often composed of cross-curricular volunteers, although this varied. For instance, in some schools, the Principal nominated the Heads of Department (HoDs), while, in others, the team might be a specific subject department. In some cases, a subject department was involved because of adverse review reports or recommendations by The Education Review Office, the official school review agency in New Zealand.

Commonly, the RF began work in a school by focussing on the school LL role in order to develop capacity through fostering internal literacy leadership and a sense of community among the literacy team. The RF also facilitated literacy knowledge and practices through demonstrations and workshops with the 
literacy team, who were then expected to experiment with particular approaches within their classrooms. Later, they shared their experiences with each other. In some cases this team then demonstrated how they applied the literacy approaches in whole staff seminars. These seminars helped widen the awareness of the possibilities of implementing literacy as a learning focus, and, at the same time, broadened the potential of the CP. Essentially, they provided a point of contact about literacy for other staff. This cross-curricular exposure to literacy became a key ingredient in fostering individual teacher buy-in in many schools, and created a footing for the development of the LCP, depending on the school's stage of development (see May, this issue).

In terms of Wenger et al.'s (2002) notions of CPs in action, 'engagement is a personal matter' (p. 36) and voluntary; this was true of most literacy teams but not always. Thus, beginning the process of developing literacy capacity began with the keenest staff. Eventually, they piqued the interest of other staff, but often in random, informal and serendipitous ways, for instance, through conversations at lunch breaks, by informal exchanges over the photocopier or by chance comments in the staff workroom. The work of an LL often helped continue the momentum of such networking about literacy, in between visits from the RF. In examples such as these, LCP members effectively widened the community's net by just going about their daily literacy work. In a sense they contributed to Wenger et al.'s (2002) observation that 'members of a healthy community of practice have a sense that making the community more valuable is to the benefit of everyone. ... it is a pool of goodwill-of "social capital"' (p. 37). In the case of literacy development in secondary school classrooms, these informal sharing opportunities have become valuable professional activities, essentially benefiting both staff within the LCP and those without.

Developing LCPs is predicated on people having both the intellectual, social and physical spaces to do so, such as in staffrooms or workrooms, contributing to both the maintenance and growth of networks, and the formal or informal flow of information. Technology also assisted. In many schools staff accessed templates for literacy lessons from shared intranet server spaces, adapting them for their own purposes, while having access to existing models. This adaptation often followed by observing teachers in action in their own classrooms, or having the approaches demonstrated in whole staff seminars. And as other staff sought to know more from members of the LCP, these teachers' professional identities and sense of self were affirmed, increasing their positive disposition towards a literacy-oriented pedagogy.

Lave and Wenger's (1991) description of legitimate peripheral participation is indicative of the kinds of practices occurring in schools successfully nurturing LCPs. In such schools, teachers' sociocultural literacy practices developed as they learned more about themselves, their pedagogies and beliefs, the role of literacy in learning and thinking and their students' learning. As Lave and Wenger (1991) point out, 'learning is an integral and inseparable aspect of social practice' (p. 31): the social practice in question is literacy. These ideas reiterate not only Gee's argument regarding the importance of a focus on learning processes and related social practices, but also Gilbert's ideas about education for the future. 


\section{External facilitation: The regional facilitator role (RF)}

RFs employed as part of the SSLI generally spent considerable time working with LLs and literacy teams to develop relationships and capacity with their allocated five cluster schools during the approximately 8 months of the allotted school year. As a result, progress could seem to be frustratingly slow; the planning and awareness-raising stages were often lengthy.

In SSLI, it was evident that few schools had previously experienced a structured, longitudinal pedagogical PD process. Cross-curricular CPs have thus been rare in New Zealand secondary schools, as elsewhere. It was also common for a school's LCP to be relatively 'unformed' until well after the RF ceased to work regularly in the school, especially if it was in an early stage of Phase 1 (see May, this issue). However, the groundwork established via the RF's intervention, and the continued work of a school's LL, meant that literacy remained a PD focus as other teachers became interested in what it had to offer. May (this issue) examines the phases of literacy sustainability that implicate LCPs. Now that more schools are aware of the possibilities of literacy to support student achievement and have been examining their own literacy knowledge and pedagogies, more now use practices that foster sharing and professional discussions and support among staff. Essentially, these are LCPs.

School achievement data, collected and analysed by RFs and/or LLs, and presented to staff, has been crucial in raising awareness of the literacy needs of students (cf. Whitehead, this issue). From this point, it was not uncommon for teachers to realise the nature of their educative task, and better understand existing learning issues. Consequently, this exposure to well-analysed data and its implications for teachers' pedagogy was often a precipitating factor in their literacy project involvement. For instance, one LL received an email from a colleague who had just completed such literacy PD. The email said it was a 'Road to Damascus experience' for her PCK.

\section{LCPs in action: Issues and implications}

Most LCPs began with a group of volunteers, and, as alluded to earlier, the group's configuration can vary: in one SSLI school, the principal wanted HoDs in this team; in another, early-career teachers; in another, all staff were invited. Another focussed on one or two specific subject areas. One school centred literacy development attention on specific classes, involving all of their teachers.

When the Education Review Office, which is responsible for formally reviewing schools in New Zealand, made adverse comments about pedagogical or content knowledge and/or student achievement in particular subject departments, such departments were prompted to be involved in literacy; sometimes reluctantly and with some degree of negativity. In other cases, the school's LL was so highly respected that staff were keen to learn from that expertise. Some principals also targeted the careers of some teachers, approaching them to join the literacy team. Other principals just wanted to shift some teachers' thinking and practices, believing that literacy was a way to achieve it.

Exposure to well-analysed data also created opportunities for both crosscurricular talk and departmental/subject discussions, and coupled with opportunities to develop PCK, often enlightened teachers, as the example earlier 
indicated. Data about their own students also made it harder for teachers to argue that literacy had nothing to do with their subject, although this was an idea still expressed by some teachers. Mathematics teachers, in particular, were over-represented in this group. Some art teachers argued that their field was centred on visual images, forgetting the highly complex vocabulary and concepts involved. Conversely there were, and are, art and mathematics teachers who are passionate literacy advocates, but who become frustrated by the negative assumptions and perceptions of their subject peers. For smaller subject areas, such as art, there exists the added complication of competing with larger departments for literacy time and resources. Some teachers felt marginalised as a result. Such perceptions often influenced the degree to which individuals engaged with literacy approaches and the LCP.

Thus, while engagement may, indeed, be a personal matter (Wenger et al., 2002), sometimes that engagement was externally initiated. It became an intrinsic motivation in most schools involved in the SSLI once students responded positively to the teachers' efforts. Some people outside LCPs, however, remained either neutrally peripheral, or negatively affected the motivation and/or dispositions of those inside LCPs. For example, a few teachers expressed fervent views about the mismatch between the school's literacy focus and what they believed were reasons for students' low achievement, often in highly deficit terms, while others excluded themselves for reasons such as imminent retirement, pregnancy or illness. In one school members of one department wanted to wait for a year, until the new HoD and other new staff had time to find their feet.

Those who believed that they were unable to do much with the students they taught, expressed the kinds of deficit views about students exposed by Bishop and Berryman (2006), who examined indigenous Maori students' schooling experiences and achievement by investigating the perceptions of teachers, students and parents. A key finding from this research was that teachers' attitudes and assumptions about both who the learners were and what they believed about their pedagogical role, were critical. The negative beliefs and assumptions about learning held by some teachers, and their associated views of pedagogy, sometimes had a ripple effect, detrimentally undermining others' attempts to change their practices, beliefs and attitudes. This will be expanded further in the next section.

\section{Communities of Practice and Spaces}

While the literature on CPs necessarily focusses on examining the communities themselves, it often fails to deal adequately with the wider organisational contexts in which they exist (cf. May; Smyth, this issue). These contexts influence the degree to which CPs may flourish. Without the strong and active commitment of a school's principal and other leaders to negotiate strategies and structures, and PD with external facilitators, literacy as a pedagogical change focus usually faltered because systemic conditions were not established to support literacy. A CP is not a panacea for change, of or by, itself. Instead, it describes how common interests can converge, develop and grow, based on shared experiences that emerge from, in this case, teachers wanting to learn, experiment, reflect on and share their literacy pedagogical practices. It is indeed, a 'personal matter', 
but it is also a professional one. Collegial interaction, opportunities for developing PCK and leadership focussed on literacy grows LCPs. External facilitation input can be important to this growth. Systemic mechanisms that provide space, leadership and effective relationships for LCPs to flourish are considered next.

Space encompasses both physical, such as appropriate rooms for meetings, and emotional (for example, feelings, perceptions, relationships) spaces. Appropriate physical spaces are those which make it easy for teachers to congregate and engage in new learning, sharing what happens when they experiment in their classrooms. It may be that other staff observe teachers in action in classrooms, but teacher-only spaces are necessary too. These physical spaces need to be separate from the daily business of schools. If teachers are to alter their professional identities, then the associated risks of interruption and privacy must be managed.

Some schools and RFs conducted PD sessions off-site. This strategy was particularly pertinent when SSLI regional facilitators (RFs) brought teachers together from different schools as a practicality where geography made it difficult for RFs to regularly travel to individual schools. Some participants had long journeys as a result, but commented on how useful the travel time was as brainstorming and planning sessions, since at least two people travelled to the PD together. They also enjoyed both the physical distance from school and the networking opportunities at the meetings, fostering a regional LCP. In other areas, RFs brought school LLs together to encourage other networks of literacy practice, supported by the more prosaic aspects of the 'personal matters' (Wenger et al., 2002) of lunches and refreshments.

Emotional spaces refer to Hargreaves' (1997) ideas about teachers' work. He suggests that, 'good teaching is not just a matter of being efficient, developing competence, mastering technique and possessing the right kind of knowledge. Good teaching also involves emotional work' (p. 12). In fact he uses the term 'emotionally charged' (p. 13) to describe teachers' work and planning. Emotional spaces are those in which teachers have time to think, reflect and plan new ways of working with students. Secondary teachers in New Zealand, at least until very recently, taught for most of the school day. ${ }^{2}$ Therefore, the relentless busy-ness of the school day and the continual proximity to others (staff and students) generally precluded opportunities for reflective thought. A lack of intellectual, reflective and emotional space has a negative impact on teachers' work. When teachers commit to a PD programme such as literacy, they must carve out time from their school day to do so, and this is not easy. As Hargreaves (1997: 11) observes, 'overburdened teachers are likely to live off past preparation when teaching ... in order to accommodate additional ... responsibilities that are supposed to benefit ... students'. Finding ways to adjust or adapt timetables can be instrumental in carving out time. Handy and Aitken (1986) claimed that '... a prerequisite for engagement and significant school change is an increase in the amount of time teachers have to study their teaching and ... develop appropriate practices' (p. 388). Even though this observation is over 20 years old, it still highlights the role school leadership plays in supporting teacher change; space is an organisational and leadership concern.

Sometimes new ways of structuring learning can contradict a teacher's preferred pedagogical patterns. For instance, if teachers are most comfortable 
using transmissionist teaching, they may be hesitant and fearful of instigating lessons in which students work in groups and discuss problems/tasks together, methods which shift the locus of control from teacher to student. This may cause the teacher a great deal of anxiety; experimenting with pedagogy is, therefore, an emotional, personal enterprise, because reframing beliefs and attitudes about teaching, learning and students is often about how teachers see themselves. Consequently, literacy PD can create both disruption and unease, and exhilaration when students respond positively to more effective literacy approaches.

Positive literacy leadership is critical: principals play a key role in supporting LCPs. Principals provide resourcing and target key school staff: LLs and literacy teams. LLs are crucial to the growth and longevity of LCPs, for they are the hub of a network of literacy people - the literacy team, RFs, the principal and other teachers (cf. May, this issue). They link people together, cementing expertise and mentoring relationships and support staff in sharing resources, plus negotiate the timing, content and focus of overall school literacy plans. As Gunter (2001) has observed, 'leadership... is a context-specific professional relationship' (p. 17) which LLs negotiate daily. Because SSLI revealed the central role LLs play in stitching together and maintaining the momentum of LCPs, their relational role involves literacy and leadership.

Effective relationships are an important factor in the long term success of LCPs. A consistently reported item in the SSLI evaluation was the high level of respect for key players in the literacy PD, such as the LL and/or principal, or RF, a key factor in teachers maintaining their literacy involvement. The role relationships play-both positively and negatively -is not well served in the literature on communities of practice. For instance, Hanks' introduction to Lave and Wenger (1991) suggests that CPs are principally about the 'relationship between learning and the social situations in which [they] appear' (p. 14). This downplays relationships between individuals inside or beyond LCPs.

Lave and Wenger maintain that CPs are often flatter in their structure because members learn off each other. This might imply that a $\mathrm{CP}$ is organic and grows itself. However, two things are needed: purposes through which this learning (that is, literacy) and symbiosis occur; and people to initiate and sustain momentum, relationships and literacy networks. Successful SSLI schools' LCPs exhibited such factors. Central leading figures were the LL and an actively supportive principal and/or senior management team.

Relationships between those within the LCP and those outside it have been alluded to earlier. For instance, in some SSLI schools, some subject department members were part of the LCP, while others were not. This did not always make for genial departmental relationships for a number of reasons: some were passively resistant to literacy; some professed indifference (for example, because of impending retirement) and some were actively resistant, making it difficult for colleagues to openly discuss their literacy classroom experiments.

When HoDs were resistant, it could precipitate (or was symptomatic of) unpleasant or dysfunctional departmental relations at its worst, or undermine respect and collegiality at its most benign. Resistant staff members, over time, became increasingly isolated. When an HoD was a known resistor, this frequently unsettled working departmental relationships. 
Even principals had difficulty with HoD resistance. In one case, a principal acquiesced when faced with an HoD's implacable opposition to literacy development. The HoD had skills important to critical aspects of the school's organisation, such as timetabling. This was a strategic trade-off in the principal's eyes, even though this HoD's position negatively affected internal departmental relationships, as some departmental members were keen to share their literacy approaches. Similar sources of conflict are infrequently addressed in CP literature.

\section{Conclusion}

The development of literacy across the curriculum in New Zealand secondary schools is a work in progress. It is a project spanning all content areas and precipitates teachers talking across subject boundaries. As such, it is an uncommon PD focus in secondary schools. For those involved, it has often re-invigorated their pedagogical passion. This can be traced to not only teachers feeling safe enough within supportive LCPs to experiment with their teaching and report on it, but also to the positive responses from students and accompanying improvements to their achievements. Through sharing, teachers gain the mutual respect of their colleagues and learn about respective subject disciplines and expertise. The job of the school's LL is a critical factor, sustaining the momentum through activities such as networking, providing access to literacy resources, individual and group PD, brokering external PD through the facilitators and other sources and lobbying the principal regarding resources. Provided, of course, they have a time allowance to do so; this too is a critical element for longevity.

A whole-school focus on literacy grows mainly from volunteer teams, initiating an LCP. Because the members of this group are usually representative of most subject areas, there is potential for LCPs to spread more widely. On the other hand, opposition to such a whole-school pedagogical focus can, negatively, affect relationships within and across departments. It can, however, be minimised, particularly when LCPs develop a critical mass across subjects, and when a school's leadership is committed to literacy by creating positive conditions for it to flourish.

Thus, the communities of practice literature is useful as a tool with which to examine how teachers can collectively develop and sustain their knowledge about practices of literacy, reframing their professional identities. However, the current CP literature falls short of accounting for wider contextual influences, particularly the effects of working in organisations where some are members of CPs, and some are not. This may be particularly important for schools, since size is a contextual influence, particularly at the secondary level.

Subject departments are subsets of the whole staff, with specific interests and knowledge. LCPs have the potential to cross subject boundaries. The regular proximity to other teachers can be significant in both positive and negative ways as they share feelings, ideas, perceptions, experiences or prejudices very readily. The likelihood of LCPs gaining traction and surviving for a long time may be dependent on the strength of key literacy players in the school to not only minimise the potential or actual negativity of others regarding literacy, but also to maintain momentum through positive interactions, systemic mechanisms and literacy interventions. 


\section{Correspondence}

Any correspondence should be directed to Dr Noeline Wright, School of Education, University of Waikato, Private Bag 3105, Hamilton 3240, New Zealand (noelinew@waikato.ac.nz).

\section{Notes}

1. Opinions expressed in this report are those of the author and do not necessarily coincide with those of the New Zealand Ministry of Education.

2. For example, over a 25-hour teaching week, teachers were with classes for 23 of them, as well as doing lunchtime/breaktime duties and/or organising extra-curricular activities before or after school, and weekends. In some cases, the non-contact hours were used to cover sick colleagues' classes.

\section{References}

Aitken, C.H.R. (1986) Understanding Schools as Organisations. London: Penguin.

Albrecht, K. (2003) The Power of Minds at Work. San Francisco, CA: American Management Association.

Bishop, R. and Berryman, M. (2006) Culture Speaks: Cultural Relationships and Classroom Learning. Wellington, NZ: Huia.

Buysse, V., Sparkman, K.L. and Wesley, P.W. (2003) Communities of practice: Connecting what we know with what we do. Exceptional Children 69 (3), 263-277.

Coldron, J. and Smith, R. (1999) Active location in teachers' construction of their professional identities. Journal of Curriculum Studies 31 (6), 711-726.

Corson, D. (1999) Language Policy in Schools: A Resource for Teachers and Administrators. Mahwah, NJ: Lawrence Erlbaum.

Gee, J.P. (2003) What Video Games Have to Teach Us about Learning and Literacy. Gordonsville, VA: Palgrave Macmillan.

Gilbert, J. (2005) Catching the Knowledge Wave? The Knowledge Society and the Future of Education. Wellington, NZ: NZCER.

Gunter, H. (2001) Leaders and Leadership in Education. London: Paul Chapman.

Handy, C. and Aitken, R. (1986) Understanding Schools as Organisations. London: Penguin.

Hanks, W.F. (1991) Introduction. In J. Lave and E. Wenger (eds) Situated Learning: Legitimate Peripheral Participation (pp. 13-14). Cambridge: Cambridge University Press.

Hargreaves, A. (1997) Rethinking Educational Change with Heart and Mind. Alexandria, VA: ASCD.

Lave, J. and Wenger, E. (1991) Situated Learning: Legitimate Peripheral Participation. Cambridge: Cambridge University Press.

Marcus, H.R. and Kitayama, S. (1994) The cultural construction of the self and emotion: Implications for social behaviour. In S. Kitayama and H.R. Marcus (eds) Emotion and Culture: Empirical Studies of Mutual Influence. Washington, DC: American Psychological Association.

Ministry of Education (2003) Learning for tomorrow's world: New Zealand summary report. http://www.educationcounts.edcentre.govt.nz/research/pisa/pisa2003.html. Accessed 07.05.07.

Moje, E.B., Dillon, D.R. and O'Brien, D. (2000) Re-examining roles of learner, text, and context in secondary literacy. Journal of Educational Research 93 (3), 165-180.

Morris, A. and Stewart-Dore, N. (1984) Learning to Learn from Text: Effective Reading in the Content Areas. North Ryde, NSW: Addison-Wesley.

Place, N.A. and Coskie, T.L. (2006) Learning from the national board portfolio process: What teachers discovered about literacy teaching and learning. The New Educator 2, 227-246.

Programme for International Student Assessment (PISA) (2003) Learning for TomorrowNew Zealand Summary Report. Wellington, NZ: Ministry of Education.

Putnam, R.T. and Borko, H. (2000) What do new views of knowledge and thinking have to say about research on teacher learning? Educational Researcher 29 (1), 4-15. 
Wenger, E. (1999) Communities of Practice: Learning, Meaning, and Identity. Cambridge: Cambridge University Press.

Wenger, E., McDermott, R. and Snyder, W.M. (2002) Cultivating Communities of Practice. Boston, MA: Harvard Business School Press.

Wright, N. (2003) Sharp learning tools versus blunt axes - our pedagogical heart. English in Aotearoa 51 December, 4-11. 
Copyright of Language \& Education: An International Journal is the property of Multilingual Matters and its content may not be copied or emailed to multiple sites or posted to a listserv without the copyright holder's express written permission. However, users may print, download, or email articles for individual use. 